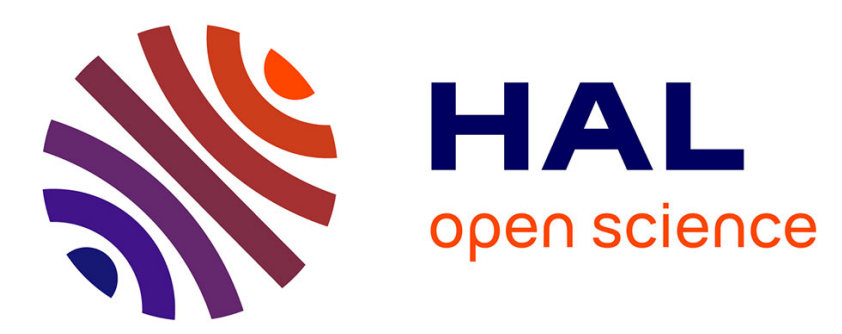

\title{
Thermodynamical behaviour of domain walls in ordered alloys: an experimental study by transmission electron microscopy
}

\author{
A. Loiseau, C. Ricolleau, E. Cabet
}

\section{- To cite this version:}

A. Loiseau, C. Ricolleau, E. Cabet. Thermodynamical behaviour of domain walls in ordered alloys: an experimental study by transmission electron microscopy. Journal de Physique IV Proceedings, 1993, 03 (C7), pp.C7-2057-C7-2062. 10.1051/jp4:19937329 . jpa-00251975

\section{HAL Id: jpa-00251975 https://hal.science/jpa-00251975}

Submitted on 1 Jan 1993

HAL is a multi-disciplinary open access archive for the deposit and dissemination of scientific research documents, whether they are published or not. The documents may come from teaching and research institutions in France or abroad, or from public or private research centers.
L'archive ouverte pluridisciplinaire HAL, est destinée au dépôt et à la diffusion de documents scientifiques de niveau recherche, publiés ou non, émanant des établissements d'enseignement et de recherche français ou étrangers, des laboratoires publics ou privés. 


\title{
Thermodynamical behaviour of domain walls in ordered alloys: an experimental study by transmission electron microscopy
}

\author{
A. LOISEAU ${ }^{*, * *}$, C. RICOLLEAU ${ }^{* * * *}$ and E. CABET ${ }^{*}$ \\ ${ }^{*}$ Laboratoire de Physique du Solide, ONERA, BP. 72, 92322 Châtillon cedex, France \\ ** LEM/CNRS, ONERA, BP. 72, 92322 Châtillon cedex, France
}

\section{INTRODUCTION}

Numerous $\mathrm{A}_{3} \mathrm{~B}$ binary alloys are ordered at low temperature on a given lattice (BCC or FCC) and become disordered on this lattice at high temperature. This transition can be of first or second order depending on whether the long range order parameter goes to zero discontinuously or not. In the first case, there is a two-phase field except at the congruent point. In any case, the transition is characterized by a loss of symmetry and the simplest situations occur when the ordered structure is cubic: in this case, there is only a loss of translational symmetry which implies the formation, during the ordering process, of translational variants (or domains) bounded by domain walls, called antiphase boundaries (APB).

In this paper, we present experimental studies of the thermodynamic behaviour of these boundaries when approaching the order-disorder transition from below. In the case of a first order transition studied in the Cu$17 \%$ Pd alloy, which orders on the FCC lattice according to the L12 structure, we show that the APB's are wetted by the disorder and that their width logarithmically diverges at the transition in agreement with statistical physics calculations. A second order transition has been studied in the $\mathrm{Fe}-27 \% \mathrm{Al}$ alloy between the ordered structures $\mathrm{DO}_{3}$ and $\mathrm{B} 2$ built on the BCC lattice. A different behaviour is observed and the observations are consistent with the theoretically expected power law.

\section{FIRST ORDER TRANSITION}

The simplest situation is the transition $\mathrm{L}_{2}$ - disordered $\mathrm{FCC}$. The $\mathrm{L}_{2}$ structure is obtained by placing $\mathrm{B}$ atoms at the vertices of the cube and the $A$ atoms at the face centers. The translation vectors lost during the transition being of type $\langle 1 / 2,1 / 2,0\rangle$, there are three kinds of APB's characterized by one of the displacement vectors: $1 / 2[110]$, $1 / 2[101]$ and $1 / 2[011]$. As a consequence APB's obey precise extinction contrast rules: considering a given dark field image formed with a superstructure reflection, two kinds of APB's are visible and the third one is out of contrast [1]. An example is given in figure 1.

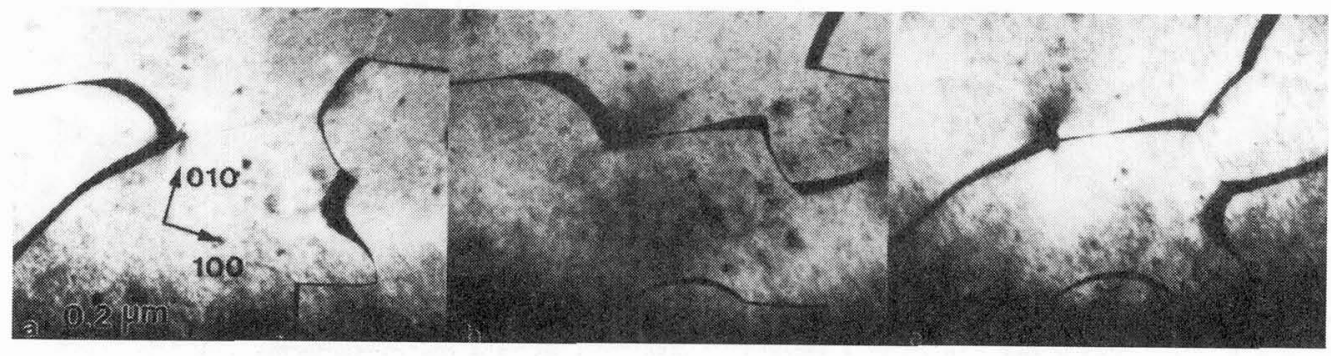

Figure 1: Complementary dark field images (DF) of perfect APB in Cu-17\%Pd: (110) in a), (210) in b), (120) in c),

It has been shown qualitatively that in various $\mathrm{L}_{2}$ compounds $[1,2,3]$, APB's have a behaviour typical of interfacial wetting: when increasing the temperature up to a few $10^{-2} \mathrm{Tc}$ below the transition temperature, a boundary extends over a few atomic planes which become partially disordered. As shown in figure $2 \mathrm{a}$, the APB is progressively split into two new interfaces of width $\xi$. At the transition, the width of the domain walls diverges i.e. 
becomes macroscopic as compared to the domain size and the disordered phase is stable. Figure 3 illustrates the phenomenon in $\mathrm{CoPt}_{3}$ in high resolution electron microscopy imaging.
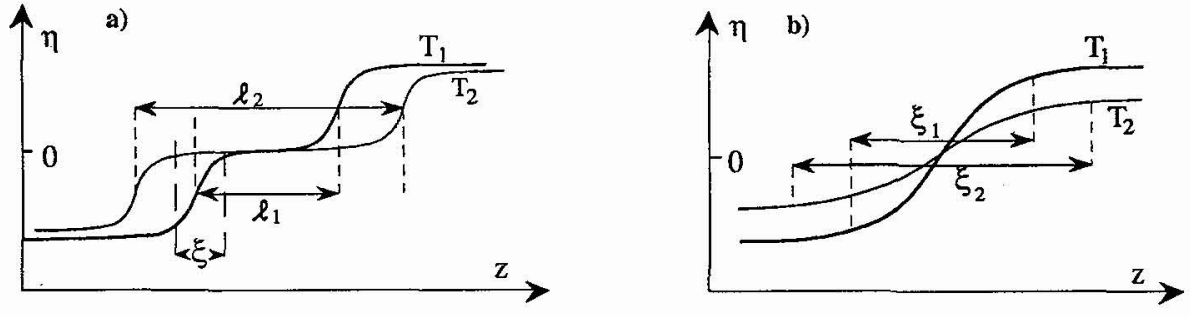

Figure 2: Evolution of the APB profiles of the order parameter $\eta$ for a first order transition in a) and a second order transition in $b$ ): $T_{1}<T_{2}, \&$ is the width of the disordered layer and $\xi$ the correlation length.

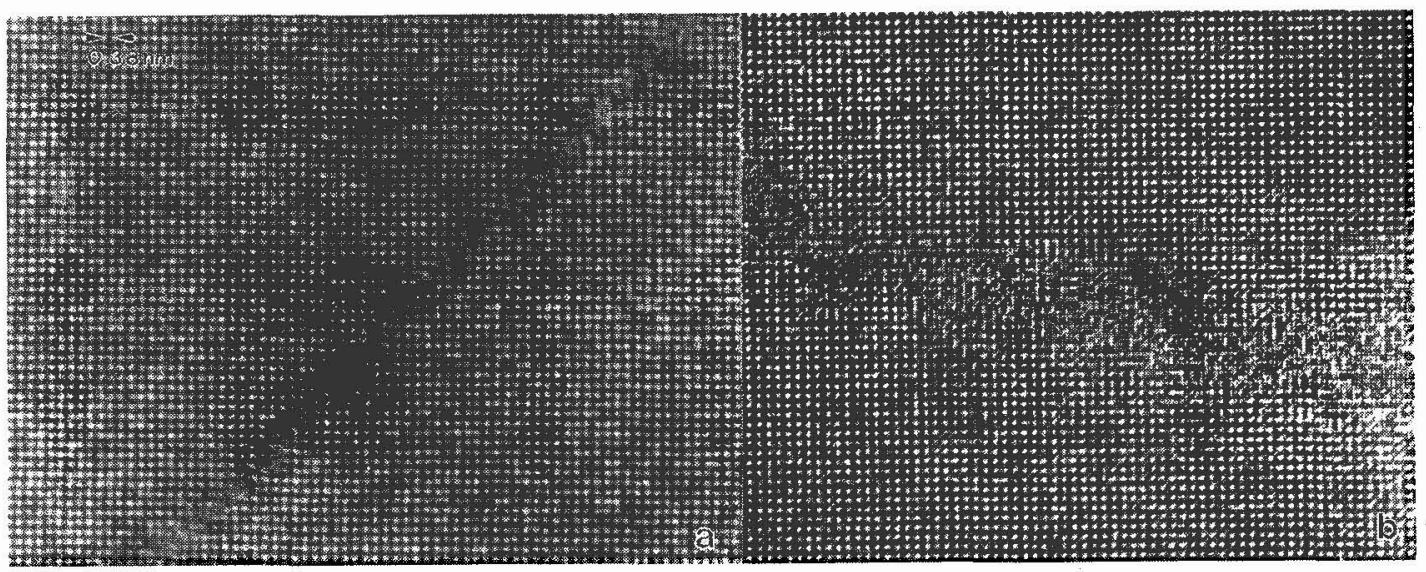

Figure 3: High resolution image of a APB in $\mathrm{CoPt}_{3}$ projected along a cube axis. a) sharp APB: within the domains, the square patterns of white dots image the columns of minority atoms. At the APB, the pattern is displaced by the vector $1 / 2[110] . . b$ ) Wetted APB: within the APB, the dot pattern is that of the disordered FCC lattice over a distance of about $4 \mathrm{~nm}$.

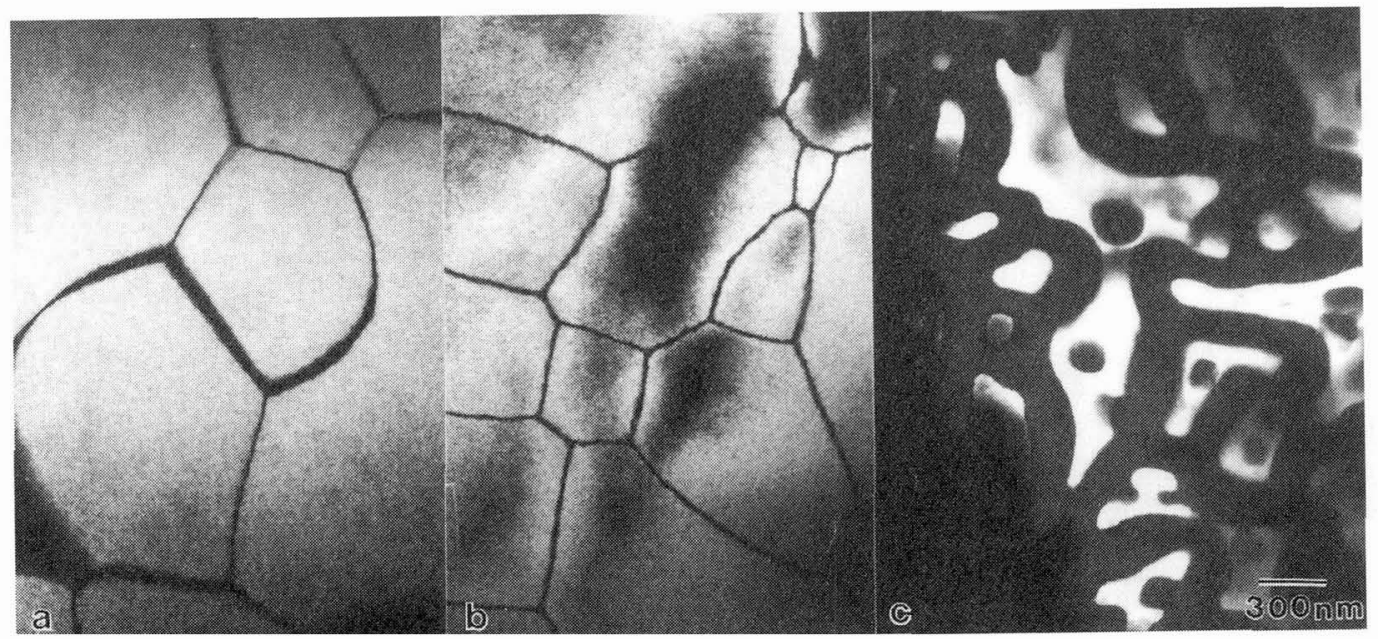

Figure 4: (110) DF images in $\mathrm{Cu}-17 \% \mathrm{Pd}$ showing the evolution of the APB contrast as a function of temperature: $498.6^{\circ} \mathrm{C}$ in a), $505.2^{\circ} \mathrm{C}$ in b) and $506.55^{\circ} \mathrm{C}$ in $\mathrm{c}$ ). 
In dark field imaging, this disorder induces a residual contrast for the APB which should be out of contrast [1], as shown in Fig 4a. As the temperature increases and the disorder is more pronounced, the APB contrast is progressively replaced by that of a thin disordered film which appears naturally dark in any superstructure DF image (figure $4 \mathrm{~b}$ ). At the transition, the disordered phase becomes stable and the two phases can coexist at equilibrium if the alloy concentration is not that of the congruent point. The disordered phase takes place at the APB giving rise to the typical microstructure shown in figure $4 \mathrm{c}$, where each ordered domain is surrounded by a thicker and thicker layer of the disordered phase. It is worth noting that this microstructure is similar to that of the well known $\gamma / \gamma$ superalloys.

Evidence for wetting has not only been observed for APB in $\mathbf{L} \mathbf{1}_{2}$ compounds near the order-disorder transition. In particular, it has been shown that in $\mathrm{Cu}_{3} \mathrm{Au}$ grain boundaries, twin boundaries at least, are also wetted [ 2 ]. It is worth mentioning that similar phenomena have been recognized for order-disorder transitions involving translation and rotation domain walls. Such situations occur when the low temperature ordered phase has a lower rotation symmetry than the disordered lattice. An example has been observed in $\mathrm{Pd}_{3} \mathrm{~V}$ which orders on the fcc lattice according to the $\mathrm{DO}_{22}$ quadratic structure. In that case comparative superstructure dark field images show that both APB and rotation interfaces (twins) are wetted by the disordered phase (Figure 5).



Figure 5: Microstructure in $\mathrm{Pd}_{3} \mathrm{~V}$ along the001 zone axis. a) DF image obtained with the different superstructure reflections due to the three orientation variants, i.e. 110 (variant $Z$ ), 11/20 (variant $Y$ ) and 1/210 (variant $X$ ): dark layers are then disordered area, which have taken place at the APB, indicated by the letter $B$ and at the interfaces between variants, indicated by the letters $A, C$. Compare this image with (11/20) DF in b), (1/210) DF in c) and (110) DF in d) which image variants $Y, X$, $\mathrm{Z}$ respectively.

A phenomenon similar to wetting has also been identified in an order-order transition between two structures $\mathrm{Ll}_{2}$ and $\mathrm{L}_{1}$ ordered on the fcc lattice in Co-Pt alloys [4]. L1 $1_{2}$ is the high temperature phase, and $\mathrm{L1} 1_{0}$ the low temperature phase, which has the particularity to be quadratic and to display three kinds of rotation variants. When lowering the temperature, each kind of APB occuring in $\mathrm{L1}_{2}$ is wetted by a given rotation variant of $\mathrm{L} 1_{0}$ as shown in figure 6. This phenomenon also gives rise to particular APB contrast in DF images (figure 7)

Wetting definitely appears as a very general phenomenon occuring qualitatively in various kinds of ordering transitions in alloys. In the following, we present a quantitative characterization in the simplest case of $\mathrm{APB}$ in $\mathrm{Ll}_{2}$ wetted by the disordered phase. 
Detailed experiments, using electron microscopy characterization on samples annealed at different temperatures between $498^{\circ} \mathrm{C}$ and $507^{\circ} \mathrm{C}$ and quenched, have been performed to determine quantitatively the nature of the divergence of the APB width in the Cu-17\%Pd alloy [5]. A preliminary study has shown that a two-phase field takes place over $1^{\circ}$ between $\mathrm{Tc}_{1}=505.6^{\circ} \mathrm{C}$ and $\mathrm{Tc}_{2}=506.6^{\circ} \mathrm{C}$ and that premonitory effects of wetting start $10^{\circ} \mathrm{C}$ below $\mathrm{Tc}_{1}$ [3]. Details of the experimental procedure for the sample preparation and of the APB characterization are given in [5]. The APB width is measured from the width of the residual contrast of the APB's seen edge on in DF imaging.

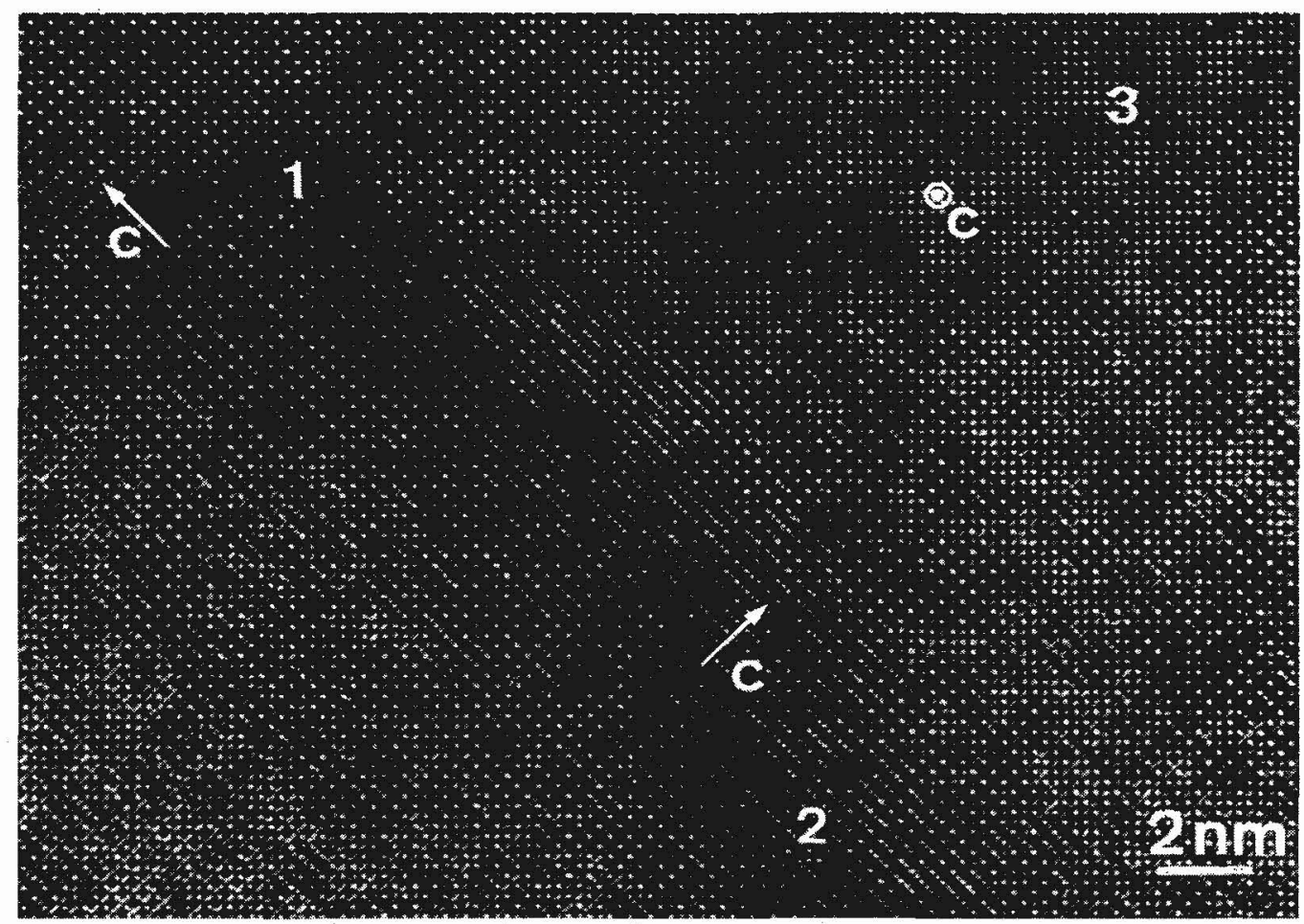

Figure 6: High resolution image along the 001 zone axis of a node of three APB in $\mathrm{Co}_{37} \mathrm{Pt}_{63}$ ordered with the $\mathrm{L}_{2}$ structure White dots image the Co atomic columns.. Each APB is transformed in a thin $\mathrm{L} 1_{0}$ layer, which is the variant $\mathrm{Y}$ for APB 1 , the variant $X$ for $A P B 2$ and variant $Z$ for APB 3 .

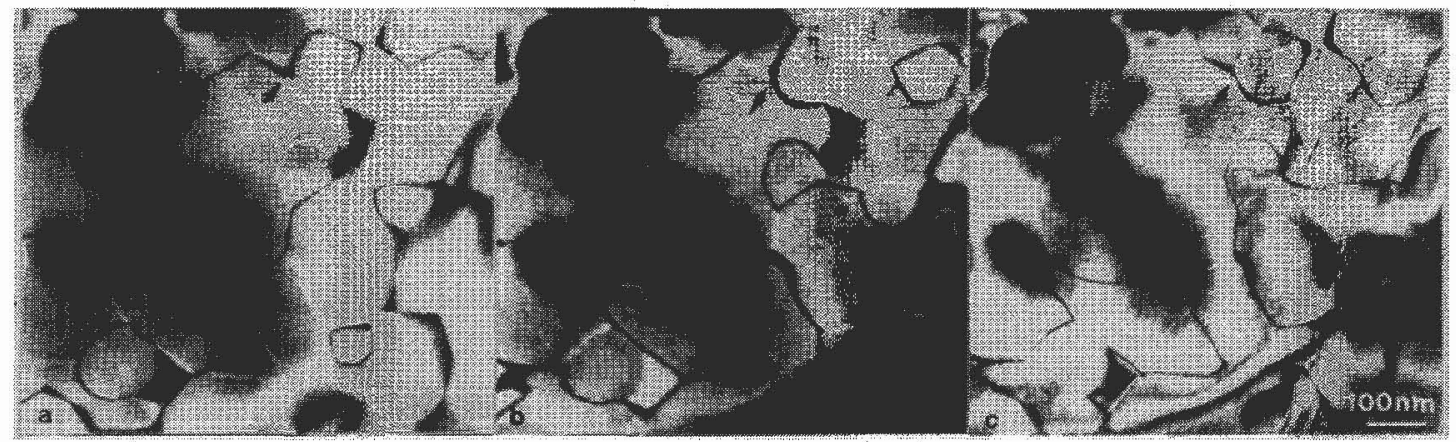

Figure 7: Comparative DF images showing the microstructure of the APB in $\mathrm{Co}_{37} \mathrm{Pt}_{63}$ ordered with the $\mathrm{L}_{2}$ structure: (110) in a), (210) in b), (120) in c). The APB which should be out of contrast in a given dark field appears with a white contrast because of the wetting by $\mathrm{Li}_{0}$.

The evolution of the APB width $\ell$ with temperature is shown in figure $8 \mathrm{a}$. Up to $505.4^{\circ} \mathrm{C}$, the APB width increases but remains below $7 \mathrm{~nm}$ and at $505.6^{\circ} \mathrm{C}$ it abruptly jumps to $18 \mathrm{~nm}$ : this corresponds to a significant change of scale between a microscopic regime (fig. $4 \mathrm{a}, \mathrm{b}$ ) and a macroscopic one (fig.4c) which allows us to differentiate a two-phase situation from the wetting phenomenon occuring below $\mathrm{Tc}_{1}=505.6^{\circ} \mathrm{C}$. The variation of 
$\ell$ with temperature in the wetting regime has been analysed in detail. A $\log \log$ plot clearly shows that $\ell(T)$ does not obey a power law in the form of $\left(\mathrm{Tc}_{1}-\mathrm{T}\right)^{-\alpha}$ and suggests a logarithmic law $\ln \left(\mathrm{Tc}_{1}-\mathrm{T}\right)$. Figure $8 \mathrm{~b}$ shows the best linear fit given for a semi $\log$ plot obtained for $\mathrm{Tc}_{1}=505.6^{\circ} \mathrm{C}$.
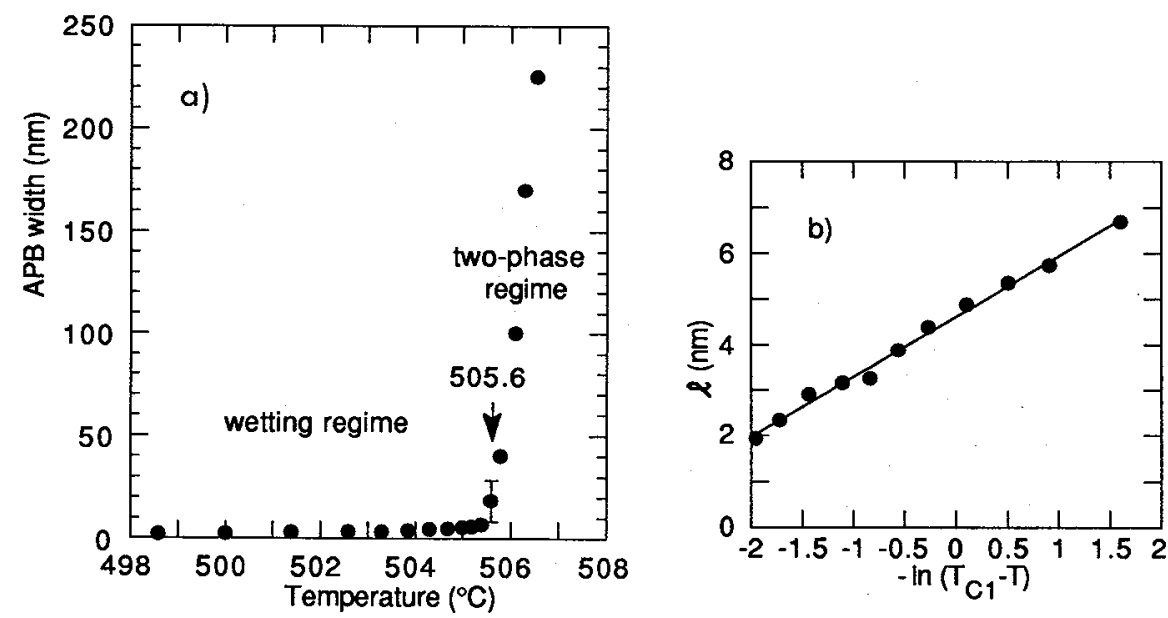

Figure 8: a) Evolution of the APB width $l$ as a function of temperature. b) $l$ as a function $\ln \left(\mathrm{Tc}_{1}-\mathrm{T}\right)$ for $\mathrm{Tc}_{1}=505.6^{\circ} \mathrm{C}$.

This clearly proves that wetting of APB's obey a logarithmic law in agreement with statistical mechanics calculations[6]. At $\mathrm{Tc}_{1}, \ell$ diverges but its value at this temperature remains finite and is about $9 \mathrm{~nm}$. This is due to the presence of the two-phase field. In the wetting regime, $\ell$ should remain negligible with respect to $D$, the domain size, whereas $\ell / \xi, \xi$ being the extension of the new interfaces, diverges. Thus, for a finite domain size D, the wetting regime yields a cross over regime, when $\ell / D$ becomes significant and corresponds to a significant volume fraction of disordered phase. At this moment, the two-phase regime starts and the transition is continuous within the APB. The maximum value of $\ell$ in the wetting regime thus depends on D. In [5], we present a simple model which allows us to describe the cross over regime yielding values of $\ell$ and $\xi$ in fair agreement with experiments.

\section{SECOND ORDER TRANSITION}

Second order transitions are less commonly observed than first order transitions but can occur on the BCC lattice. We have chosen to study the transition between the $\mathrm{B} 2$ and $\mathrm{DO}_{3}$ phases of the $\mathrm{Fe}-\mathrm{Al}$ system, which is known to be of second order [8]. Both phases have cubic ordered structures built on the BCC 1attice. B2 is obtained by placing $\mathrm{B}$ atoms at the vertices of the cube and A atoms at the center. B2 then consists of two interpenetrating simple cubic sublattices and $\mathrm{DO}_{3}$ corresponds to a further ordering on one of these sublattices where all edges are $\mathrm{AB}$ pairs. The only translation vector lost during the transition being [100], there is only one kind of APB, which is always in contrast in a dark field image made with the superstructure reflection of $\mathrm{DO}_{3}, 1 / 2(111)$.

The evolution of the APB with temperature has been studied in the $\mathrm{Fe}-27 \% \mathrm{Al}$ for which the transition temperature is $\mathrm{Tc}=547^{\circ} \mathrm{C}$ [7]. The samples were first ordered at $450^{\circ} \mathrm{C}$ for developing $\mathrm{DO}_{3}$ domains, quenched and then heated in the microscope step by step up to Tc.The observed phenomena we describe now are completely reversible and are not spoiled by any contamination or oxidation. The qualitative evolution of the APB profile is sketched in figure $2 \mathrm{~b}$. The APB profile is progressively smoothed over a width $\xi$ which becomes infinite. In the same time, the order parameter within the domains progressively decreases to zero.

The APB have been imaged using DF images as follows. Because of the unicity of the APB type and of the $\mathrm{DO}_{3}$ superstructure reflection type, the APB are always in contrast in DF images. Consequently, the contrast rules working for $\mathrm{L1}_{2}$ cannot be used for detecting disordering at the APB. Nevertheless, considering the behaviour and the APB profile theoretically expected as a function of temperature, it can be analytically shown that the fringe intensities due to the APB will decrease exponentially as a function of $\xi \mathrm{s}, \xi$ being the correlation length and $s$ the Bragg deviation. One therefore expects from APB image simulations that the fringe contrast at large s progressively disappears when increasing $\xi$ and that this attenuation affect DF images for smaller and smaller s values This is exactly what we observe experimentally when heating a sample in the microscope. The evolution of the DF images is shown in figure 9. The contrast at $s=0.1 \mathrm{~nm}^{-1}$ (figure $9 \mathrm{c}$ ) disappears at about $200^{\circ} \mathrm{C}$ below $T_{c}$ and no contrast at $s=0.08 \mathrm{~nm}^{-1}$ can be obtained at $T_{c}-100^{\circ} \mathrm{C}$. Figure $9 \mathrm{~d}$ displays a very weak contrast for $\mathrm{s}=0.06 \mathrm{~nm}^{-1}$ 
compared to figure $9 \mathrm{~b}$. At $\mathrm{T}_{\mathrm{c}}-20^{\circ} \mathrm{C}$, only a weak contrast can be obtained for $\mathrm{s}=0.04 \mathrm{~nm}^{-1}$ (figure $9 \mathrm{e}$ ). Such a progressive attenuation of the weak beam contrast is not observed for the wetted APB in Cu-17\%Pd: the fringe contrast suddenly disappears when the residual contrast increases because of the APB splitting into two new interfaces .

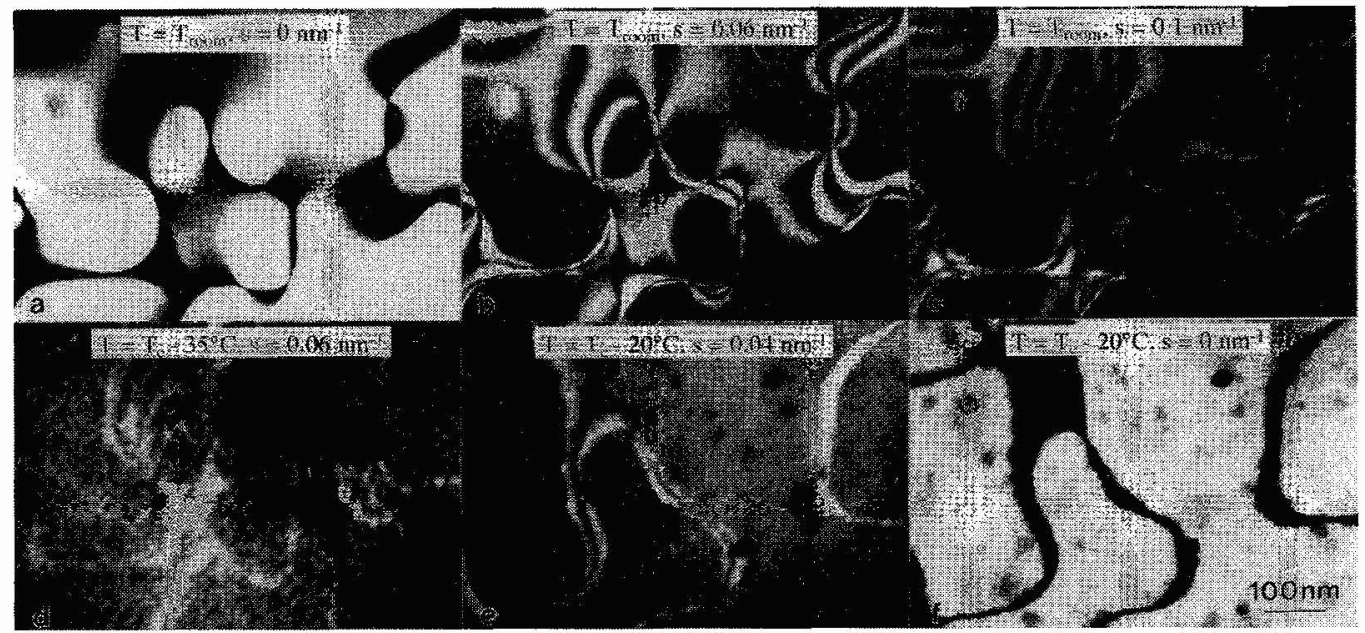

Figure 9: Dark field images of $\mathrm{DO}_{3}$ APB, a), b), c) : sharp APB ( $s=0$ in a), $s=0.06 \mathrm{~nm}^{-1}$ in $b$ ), $s=0.1 \mathrm{~nm}^{-1}$ in c)). d),e), f) : smoothed APB ( $s=0.06 \mathrm{~nm}^{-1}, \mathrm{~T}=\mathrm{Tc}-35^{\circ} \mathrm{C}$ in $\left.\mathrm{d}\right) ; \mathrm{s}=0.04 \mathrm{~nm}^{-1}, \mathrm{~T}=\mathrm{Tc}-20^{\circ} \mathrm{C}$ in $\mathrm{e}$ ); $\mathrm{s}=0.0 \mathrm{~nm}^{-1} \mathrm{~T}=\mathrm{Tc}-20^{\circ} \mathrm{C}$ in $\mathrm{f}$ ) ).

Above $T_{c}-20^{\circ} \mathrm{C}$, the only observable contrast occurs at $s=0$ (figure $9 f$ ). This contrast is nothing but the contrast of a thin disordered layer : it is no longer produced by the APB but it is due to the high disorder induced by the progressive APB spreading and its width is related to the correlation length. At this temperature, the APB width is about $20 \mathrm{~nm}$ which is much larger than the maximum width of wetted APB. Figure 10 shows the further contrast evolution when heating up to $T_{c}$. The APB width which can be measured from these images increases up to about $70 \mathrm{~nm}$ at $\mathrm{T}_{\mathrm{c}}-2^{\circ} \mathrm{C}$. Such widths correspond to widths measured in the two-phase field of $\mathrm{Cu}-\mathrm{Pd}$. Simultaneously however the contrast within the domains clearly vanishes and one can notice fluctuations whose amplitude increases when approching $T_{c}$. As a consequence, in the vicinity of $T_{c}$ (figure10d), the image contrast seems to break up and the APB contour vanishes. This marks a clear difference with the first order transition: because of the decreasing of the volumic order parameter, the APB never transform into a macroscopic layer of disordered phase bounded by two order-disorder interfaces. These observations are fully consistent with the behaviour theoretically expected and allow us to clearly differentiate between second and first order transitions. Finally, a log-log plot of the APB width as a function of $T_{c}-T$ suggests that $\xi$ obeys a power law with an exponent between 0.5 and 0.6 [9]. This is in reasonable agreement with the theoretical value 0.63 .

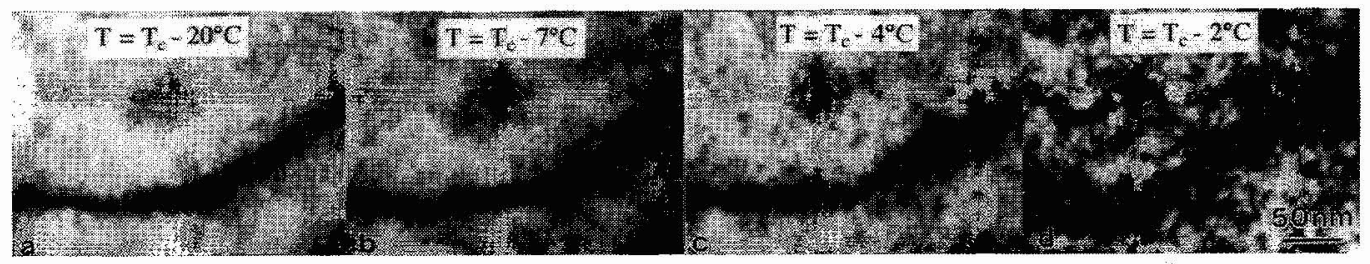

Figure 10: Dynamical dark field images of $\mathrm{DO}_{3} \mathrm{APB}$ : $\mathrm{Tc}-\mathrm{T}=20^{\circ} \mathrm{C}$ in $\mathrm{a}$ ), $=7^{\circ} \mathrm{C}$ in $\mathrm{b}$ ), $=4^{\circ} \mathrm{C}$ in $\mathrm{c}$ ), $=2^{\circ} \mathrm{C}$ in d).

[1] Leroux C., Loiseau A., Cadeville M.C., Broddin D., Van Tendeloo G.: J.Phys.: Condens Matter,2 (1990) 3479

[2] Tichelaar F.D. Schapink F.W. and Xiaofeng Li, :Philos. Mag A65 (1992) 913

[3] Ricolleau C., Loiseau A., and Ducastelle F.: Phase Transitions, 30 (1991) 243

[4] Leroux C., Loiseau A., Broddin D. and Van Tendeloo G., Philos Mag. 64 (1991) 57

[5] Ricolleau C., Loiseau A., Ducastelle F., Caudron R.: Phys. Rev. Lett., 68 (1992) 3591

[6] Finel A.: in "Ordering and Disordering in Alloys", A.R. Yavari Ed. (Elsevier, London), (1992), 182

[7] Köster W., Godeke T.: Z. Metallkde, 71 (1980) 765; Afyouni,M.: PHD Thesis, (1989), Strasbourg University

[8] Barreteau C., Loiseau A. and Ducastelle F. J. de Physique (1993) to be published

[9] Stinchcombe R.B.: in "Phase Transitions and Critical Phenomena", C.Domb, M.S. Green Eds (Academic Press, New

York), 7, (1983) chap 3 